\title{
RELACIONAMENTO TERAPÊUTICO COM CRIANÇA NO PERÍODO PERIOPERATÓRIO: UTILIZAÇÃO DO BRINQUEDO E DA DRAMATIZAÇÃO
}

\author{
THERAPEUTIC RELATIONSHIP WITH CHILD IN \\ PERIOPERATIVE NURSING CARE
}

\section{RELACIÓN TERAPÉUTICA COM EL NINO EN EL PERÍODO PERIOPERATORIO}

\author{
Fabiana Faleiros* \\ Maria Lúcia Araújo Sadala** \\ Eliana Mara Rocha***
}

Faleiros F, Sadala MLA, Rocha EM. Relacionamento terapêutico com criança no período perioperatório: utilização do brinquedo e da dramatização. Rev Esc Enferm USP 2002; 36(1): 58-65.

\section{RESUMO}

Este estudo de caso tem o objetivo de analisar o relacionamento terapêutico desenvolvido entre aluna de enfermagem e uma criança de 3 anos, durante o periodo perioperatório, utilizando o brinquedo e a dramatização para facilitar a explicação dos procedimentos e dos objetos do hospital para a criança. O uso do brinquedo mostrou-se uma forma adequada para comunicar-se efetivamente com a criança, e para prepará-la para a intervenção cirúrgica, pois, através da dramatização, ela participou ativamente dos procedimentos, mostrando que compreendia e aceitava o que estava acontecendo, não apresentando em nenhum momento medo ou ansiedade diante do ambiente do hospital e dos procedimentos cirúrgicos. Ao final do relacionamento, a mãe e a equipe cirúrgica avaliaram positivamente o preparo da criança para a cirurgia.

PALAVRAS-CHAVE: Criança. Assistência no período perioperatório. Enfermagem. Brinquedo.

\begin{abstract}
The purpose of this study was to analyse the therapeutic relationship between a nursing student and a 3 years old child during perioperative period. Through the use of careful development assessments, preoperative tours, and therapeutic play techniques her fears and anxiety because of hospitalization and surgery were reduced and the surgical experience was lived by the child in a constructive manner. Parents and peri-operative team have evaluated positively the preparation and assessment of the child for surgery.
\end{abstract}

KEYWORDS: Child. Perioperative care. Nursing care. Play.

\section{RESUMEN}

El presente estudio tiene como finalidad analizar el proceso de relación terapéutica entre alumna de enfermería y una niña de 3 años de edad durante el periodo perioperatorio. Utilizando técnicas de comunicación terapéutica y medidas terapéuticas de enfermeria, la alumna desarrolló empatia con la niña y su madre, proponiendo ayudarlas a superar sus dificultades frente sus miedos y ansiedad debida ala hospitalización y cirugia. La madre y equipo cirúgica han evaluado la preparación para la cirugia positivamente.

PALABRAS -CLAVE: Niño. Atención perioperativa. Enfermería. Juguete.

\footnotetext{
* Aluna de graduação em Enfermagem da Faculdade de Medicina de Botucatu - UNESP.

** Orientadora: Prof ${ }^{a} \operatorname{Dr}^{a}$ da Disciplina de Relacionamento Enfermeiro Paciente.

*** Cor orientadora: Prof ${ }^{a}$ da Disciplina de Enfermagem em Centro Cirúrgico.
} 


\section{INTRODUÇÃO}

A comunicação, como instrumento básico da enfermagem, permeia todo o processo da assistência, permitindo que se estabeleça, quando efetiva, um vinculo entre enfermeiro e paciente. Neste sentido, o desenvolvimento da habilidade em comunicar-se com os pacientes tem sido proposto como objetivo da comunicação e do relacionamento terapêutico. Considera-se que é possivel adquirir e desenvolver esta habilidade com fins profissionais, utilizando-a não apenas para comunicar-se efetivamente e ser compreendido pelo paciente, mas sobretudo com o objetivo de estimulá-lo a expressar-se e tomar contato com a sua realidade, da doença e da hospitalização; a partir daí, tendo possibilidades para superar as dificuldades e limitações, e lidar com a sua situação de forma realística(1-3).

$\mathrm{Na}$ assistência à criança, o papel da comunicação reveste-se de importância fundamental, uma vez que o vínculo que se estabelece entre ela e o profissional, quando efetivo, poderá atenuar os efeitos deletérios da separação dos pais e do ambiente familiar, diminuindo o estresse da hospitalização e dos procedimentos invasivos e dolorosos aos quais a criança é submetida(4). Pela comunicação efetiva, o pequeno paciente irá confiar em outra pessoa quando se sentir aceito e aprovado. Esta relação de confiança acontece e desenvolve-se nos contatos mais rápidos e simples, aparentemente banais: brincadeiras, um sorriso sincero, um olhar de atenção, um toque das mãos, o carinho ao cuidar, o lembrar o nome da criança e o conforto frente aos procedimentos médicohospitalares. São atitudes do dia-a-dia que demonstram empatia e confiança do profissional e terão, em contrapartida, a reciprocidade por parte da criança(5).

Entre as formas de comunicação com a criança, o brinquedo mostra-se como uma das mais eficientes. Estudos mostram o quão importante é o ato de brincar para o desenvolvimento sensório-motor e intelectual da criança, além de proporcionar um estímulo à independência e à aquisição de certa autonomia. A comunicação entre a criança e o adulto pode se tornar mais construtiva e oferecer mais oportunidades à criança de participar ativamente quando se utiliza o brinquedo como veículo. A forma como a criança brinca pode indicar o momento que ela está passando e como ela (6-7).

Toda criança, ao brincar, desenvolve uma atividade completamente espontânea, agradável, sem objetivos definidos, expressando uma experiência própria e pessoal. A brincadeira a leva a expressar uma reação positiva( ${ }^{(4)}$ "Ao brincar a criança libera sua capacidade de criar e reinventa o mundo, libera afetividade e através do mundo mágico do faz-de-conta, explora seus próprios limites e parte para uma aventura que poderá levá-la ao encontro de si mesma"(8).
Durante a hospitalização e especialmente nos períodos pré e pós-operatório, a necessidade de brincar deve ser suprida como se fosse uma necessidade vital, servindo de instrumento para amenizar os medos e fantasias em torno de procedimentos invasivos como as cirurgias. Nessa fase a criança se sente fragilizada, dependente, carente, desambientada, assustada, podendo ocorrer mecanismos de regressão à fase anterior do desenvolvimento. Essa regressão deixa claro a carência infantil, frente à sua situação de doente hospitalizado(9) .

As brincadeiras promovem a assimilação do mundo exterior pela criança, adaptando-se a este conhecimento de acordo com suas habilidades cognitivas e com as suas experiências anteriores. Ao mesmo tempo, promove a auto-expressão dos significados que ela atribui à realidade e ao que lhe acontece, de forma não traumática e aceitável socialmente(10). A brincadeira durante a hospitalização proporciona: diversão, relaxamento, diminuição do estresse da separação e angústia, meio de aliviar a tensão e expressar os sentimentos, interação positiva com outras pessoas, meio de expressar idéias e interesses. Por fim, proporciona uma forma de atingir os objetivos terapêuticos e a aceitação dos cuidados de enfermagem. Diante disso é interessante que o enfermeiro tenha conhecimento sobre a finalidade dos brinquedos, saiba adequá-los a cada fase da infância, para utilizá-los no ambiente hospitalar e na orientação dos pais. Neste sentido, a sala de recreação (brinquedoteca) é o setor do hospital que mais contribui para a tranqüilização e a diminuição da ansiedade nas crianças. Funciona como um santuário de paz e segurança, onde se pode trabalhar os sentimentos da criança, apesar do ambiente agressor e assustador como é o do hospital e o do centro cirúrgico(4).

O brincar, associado ao bem-estar da saúde e que tem uma função curativa, funciona como uma forma de expressar os medos e ansiedades de uma forma natural para a criança e pode ser empregado na explicação dos procedimentos cirúrgicos, facilitando a compreensão e o consentimento da criança $^{(10-11)}$

"Os objetivos da enfermagem devem estar voltados para facilitar o comportamento de adaptação frente a uma situação agressiva para a criança"(8). O brinquedo é uma forma de humanizar a assistência de enfermagem pediátrica, sendo o brinquedo terapêutico não só importante, mas essencial e indispensável ao cuidado da criança hospitalizada(12-13).

A criança internada para se submeter a uma cirurgia deve ser vista no seu aspecto global. Informações curtas, simples, incluindo a descrição da cirurgia, dos procedimentos e do centro cirúrgico contribuirão para diminuir a ansiedade, e os traumas por desconhecimento das situações. É importante que 
a criança se sinta à vontade para perguntar, esclarecer dúvidas e medos. As respostas às questões devem estar de acordo com a idade e capacidade de entendimento de cada paciente. Considera-se que o preparo préoperatório determina como será o comportamento pósoperatório da criança ${ }^{(14)}$. O brinquedo entrará nesse preparo como um instrumento facilitador da comunicação e do estabelecimento do relacionamento enfermeiro paciente: ele esclarecerá dúvidas, ajudará a criança a superar suas fantasias negativas, diminuirá a ansiedade e o medo, dará segurança e conforto ao pequeno paciente.

$\mathrm{Na}$ literatura consultada a respeito do tema, vários trabalhos enfocam a assistência à criança baseados na comunicação terapêutica. Embora tratando o tema de formas diversas, em diferentes situações, esses estudos têm como ponto central a comunicação que se desenvolve durante a assistência de enfermagem, considerada como o requisito essencial para o cuidar eficiente(9,13,15-18). Esta dimensão do cuidado, que permite ao enfermeiro relacionar-se com a criança como pessoa , com suas características e necessidades próprias, por outro lado, possibilita ao enfermeiro atuar nessa relação também como pessoa, humanizando a sua ação profissional. O paciente é, na abordagem do relacionamento terapêutico, estimulado a perceber-se como sujeito do seu próprio cuidado ${ }^{(9,17,19-22}$ ) Dentre os estudos citados, alguns descrevem o relacionamento terapêutico, desenvolvido na assistência pediátrica, utilizando o brinquedo como forma de inserir-se no contexto da criança e estimulá-la a expressar os seus sentimentos e a sua percepção a respeito do que lhe acontece $(9$ 17,19, 20, 23) Em relação ao preparo da criança para procedimentos cirúrgicos, algumas pesquisas concluem que pode ser benéfico para a criança e seus familiares a orientação e o apoio oferecidos pela equipe de saúde durante o periodo perioperatório: os resultados desses estudos ressaltam a necessidade da individualização da assistência e da preocupação com o cuidado integral da criança e família (24-29)

Como aluna graduação em enfermagem, tenho interesse especial em aprofundar meus conhecimentos na área da assistência pediátrica. Compreendo, de acordo com o que foi exposto até aqui, que o brinquedo é a forma mais efetiva de aproximação e entendimento da criança. A despeito dos evidentes beneficios da sua utilização no preparo cirúrgico da criança, na literatura encontram-se poucos artigos a respeito, refletindo provavelmente a escassa aplicação deste recurso na prática cotidiana. Proponho-me nesse estudo a investigar a utilização do brinquedo na assistência de enfermagem ao paciente pediátrico, como possibilidade de maior aproximação e comunicação mais eficiente com a criança hospitalizada, submetida a procedimentos cirúrgicos.

\section{OBJETIVO}

O objetivo do estudo é desenvolver e analisar o relacionamento terapêutico com uma criança durante os procedimentos perioperatórios, utilizando as técnicas de comunicação terapêuticas e medidas terapêuticas de enfermagem $3 / 4$ especificamente o brinquedo terapêutico e os recursos da dramatização, como estratégias para efetivar o apoio à criança e à família.

\section{PROCEDIMENTOS}

O estudo desenvolveu-se durante as atividades práticas supervisionadas da disciplina de Enfermagem em Centro Cirúrgico, no primeiro semestre de 2000, no Hospital das Clínicas da UNESP de Botucatu. No mesmo período a aluna cursava a disciplina Relacionamento Enfermeira-Paciente III, cujo conteúdo teórico-prático abrange a sistematização do relacionamento terapêutico no desenvolvimento do processo de enfermagem. Deste conteúdo, 20 horas (aulas semanais de 4 horas) são dedicadas ao ensino e à prática da comunicação terapêutica aplicada à assistência pediátrica, período no qual a aluna planejou e implementou o presente estudo, sob orientação da professora da disciplina.

O relacionamento terapêutico entre a aluna de enfermagem e a criança foi desenvolvido mediante consultas de enfermagem no pré-operatório, recepção e acompanhamento da criança no intra-operatório, sala de recuperação anestésica e pós-operatório. As interações com a criança seguiram os passos do relacionamento terapêutico: fase de pré-interação, quando a aluna preparou-se para desenvolver o relacionamento com a criança, e coletou os dados para iniciar as interações; fase inicial, que correspondeu aos contatos iniciais, de apresentação mútua entre a aluna e a paciente, quando se fez a proposta para desenvolver a assistência e a descrição dos objetivos da mesma, planejando junto com o paciente as ações para atingiremse os objetivos; fase de desenvol-vimento, quando se implementaram as ações planejadas; e fase de término, quando se finalizou o relacionamento, avaliando-se com a criança e a mãe os resultados alcançados. A criança foi escolhida, na fase de pré-interação, sem nenhum requisito prévio, aleatoriamente, de acordo com a ocorrência das cirurgias infantis de rotina(30).

A fase inicial $\left(1^{\mathrm{a}}\right.$ consulta de enfermagem, no pré-operatório) aconteceu no dia anterior à cirurgia, na unidade de internação (enfermarias) desse HC. Previamente a aluna obteve o consentimento da criança, além do consentimento livre, esclarecido e escrito do responsável pela criança, conforme as normas de pesquisa ética envolvendo seres humanos (Resolução 196 do M.S.). 
O projeto de pesquisa foi também aprovado pelo Comitê de Ética em Pesquisa da Instituição. Definiramse como objetivos da consulta: a explicação do ato cirúrgico, o esclarecimento de dúvidas e oferecimento de apoio, com a utilização de brinquedo nas explicações sobre os procedimentos cirúrgicos. A intenção foi estabelecer um relacionamento de ajuda efetivo, utilizando o brinquedo como veículo.

No decorrer dessa $1^{\text {a }}$ interação, após a fase inicial, iniciou-se a fase de desenvolvimento do relacionamento terapêutico: a criança e a mãe começaram a ser preparadas pela aluna para o ato cirúrgico, utilizando os brinquedos e a dramatização das situações hospitalares contextualizados em situações engraçadas e brincadeiras para fazer a criança sorrir, aliviar a tensão, e se sentir mais à vontade $^{(19-21)}$. Lançou-se mão, nesses procedimentos, de: bonecos (representando a equipe hospitalar, paciente, familiares), material hospitalar (seringas, gorros, máscaras, aventais, luvas), além de outros brinquedos de entretenimento (personagens de desenhos, carrinhos, nariz de palhaço, jogos, papel lápis de cor, etc).

No dia marcado para a cirurgia $\left(2^{\mathrm{a}}\right.$ interação fase de desenvolvimento do relacionamento), estabeleceu-se que eu acompanharia a criança e acompanhantes até Centro Cirúrgico, representando um ponto de referência para ela, uma vez que já se havia estabelecido entre nós uma relação de confiança. Conduzi-a até a Sala de Operação, permanecendo ao seu lado durante toda a cirurgia.

Após o procedimento, acompanhei a criança até a sala de recuperação anestésica $\left(3^{\mathrm{a}}\right.$ interação - fase de desenvolvimento), e, posteriormente, no retorno à unidade de internação. Nesses momentos desenvolveram-se mais 2 interações: no pós-operatório imediato e na enfermaria, com o objetivo de oferecer-lhe apoio, visando a diminuição do estresse provocado pelos procedimentos cirúrgicos. Essas 2 últimas interações caracterizaram ainda a fase de desenvolvimento do relacionamento. $\mathrm{Na}$ parte final da última interação foi concluído o relacionamento.

As interações desenvolvidas foram registradas imediatamente após acontecerem, descrevendo-se a comunicação verbal, a não-verbal, as reações e atitudes da criança e os brinquedos utilizados. Foram coletadas também informações do prontuário da criança, dos familiares e da equipe hospitalar, com a finalidade de subsidiar a análise dos dados do estudo.

\section{REGISTRO E ANÁLISE DAS INTERAÇÕES}

\author{
$1^{a}$ interação: fase inicial do relacionamento/ \\ fase de desenvolvimento

\section{Periodo pré-operatório}

Logo após consultar a lista das cirurgias para o dia seguinte, anotei os dados sobre uma herniorrafia em uma criança de 3 anos. Fui até a enfermaria de pediatria fazer-lhe a visita pré-operatória. Era por volta das $8: 00 h s$, a cirurgia estava agendada para as 13:00hs.

Chegando à enfermaria, providenciei uma sala reservada, onde não seríamos interrompidas e nem despertaríamos o interesse de outras crianças internadas. Também providenciei duas bonecas, equipo de soro, soro, seringa, esparadrapo, gorros, máscaras e a roupa do Centro Cirúrgico.

A mãe autorizou a participação da filha após a explicação do trabalho e seus objetivos. Recorri ao prontuário em busca de informações sobre o diagnóstico, procedimentos aos quais a criança seria submetida e dados gerais sobre ela.: I, uma menina de 3 anos, estava com hérnia inguinal bilateral.

Fomos para a sala I, sua mãe e eu. Peguei-a no colo, coloquei-a sobre a cama e apresentei-lhe as duas bonecas; a uma delas dei o nome de. I no diminutivo. Fiz algumas brincadeiras ao retirar o cobertor no qual ela estava enrolada, ela riu bastante, fomos ficando mais à vontade.

Comecei a explicar que uma das bonecas, a I , tinha duas bolinhas, uma de cada lado da região inguinal, e que precisaria retirá-las, por isso ela iria para uma cirurgia. I interessou-se, e disse que a outra boneca também iria para a cirurgia porque ela tinha uma bolinha na cabeça. Depois, simulamos uma punção venosa nas duas bonecas: puncionei uma e ela a outra, eu disse que após a cirurgia a boneca precisaria de soro, que a ajudaria a ficar boa mais rápido. I repetia na sua boneca os procedimentos que eu demonstrava na outra e se divertia.

Colocamos gorros e máscaras cirúrgicas nas bonecas, em I e em mim: expliquei-lhe que na cirurgia todos se vestiam assim. Vesti-me com a roupa azul utilizada mo Centro Cirúrgico. Associei a roupa azul a personagens infantis (telletubies), ela adorou. Após a explicação e encenação, perguntei a I o que aconteceria com a boneca e o por quê. Ela me respondeu exatamente como haviamos simulado, demonstrando que havia compreendido. Pegamos a boneca e fizemos o caminho do transporte até o Centro Cirúrgico, passando pelo elevador. Ali colocamos a boneca na maca, nos despedimos da boneca e a deixamos com as enfermeiras. Apresentei I aos funcionários responsáveis pelo transporte dos 
pacientes das enfermarias até o Centro Cirúrgico. Combinamos que mais tarde I também viria. I disse que a outra boneca viria.

Voltamos para a enfermaria, combinei com I que ela e a boneca iriam à tarde para a cirurgia, I concordou e, ao me despedir, ela queria ir comigo logo levar a outra boneca. Falei que no momento não era possível levá-la comigo, eu iria trabalhar e a cirurgia seria mais tarde. Programei com a mãe para que, na hora da cirurgia, ela levasse I até a entrada do Centro Cirúrgico junto com o funcionário, eu estaria na porta esperando por elas.

\section{Análise da interação}

O local utilizado para o desenvolvimento da visita pré-operatória foi um local calmo e reservado, o que contribuiu positivamente para o andamento da interação.

Pegá-la no colo e fazer brincadeiras com o cobertor foi uma forma de aproximação que tentei, durante um momento de ansiedade tanto para mim quanto para a I. A brincadeira fez com que nós sorríssemos e relaxássemos, facilitando o início do estabelecimento do relacionamento.

A utilização da boneca para demonstrar os procedimentos e explicar a cirurgia e sua necessidade, ajudou na compreensão da criança que, brincando, foi entendendo a realidade ${ }^{(4,20)}$ Quando I disse que a outra boneca tinha uma bolinha na cabeça e teria que ir para a cirurgia também, ela deixou transparecer sua própria experiência, pois aos dois anos ela fora submetida a uma tomografia computadorizada. Esse fato deixou claro a utilização do brinquedo pela criança como forma de expressar-se a respeito do que the acontece ${ }^{(4,6,10)}$.

Ao simular os procedimentos hospitalares, utilizar a máscara, o gorro e ver a roupa do Centro Cirúrgico, I pôde vivenciar o papel dos profissionais da equipe cirúrgica e entender melhor a função da cirurgia e das pessoas que dela participam: representando papéis dos profissionais, as crianças aprendem acerca das atividades dos adultos e das situações que lhes acontecem na assistência hospitalar (4). Associar a roupa azul a personagens infantis fez com que a criança se familiarizasse, se aproximasse e se sentisse mais próxima da equipe, já que na sua fantasia os personagens são todos seus amigos $(4,9)$

Após a encenação, estimulei I a repetir o que foi dito (encenado), como forma de validação da comunicação. O resultado foi positivo, pois ela explicou corretamente os significados daquilo que haviamos simulado, comprovando a eficácia do brinquedo para comunicar-se com a criança ${ }^{(4,19,20)}$

Fazer o caminho do transporte até o Centro Cirúrgico e depois apresentá-la aos funcionários foi uma forma de familiarizar I com uma situação que posteriormente ela vivenciaria.
Quando combinamos que mais tarde I iria até o Centro Cirúrgico, ela novamente utilizou a boneca para se expressar dizendo que a outra boneca é que viria.

Ao me despedir, I insistiu em ir comigo: tive que dizer não e estabelecer limites, explicando os meus motivos, só então ela aceitou. Pedi à mãe que acompanhasse a filha até a entrada do Centro Cirúrgico para a criança sentir-se mais segura durante o transporte.

Nesta interação analiso que utilizei o brinquedo e a dramatização das situações como linguagem para ser compreendida pela menina ${ }^{(4,10)} \mathrm{Em}$ todas as situações procurei formas terapêuticas de comunicação: utilizei técnicas para estimular a sua expressão, demonstrei verbal e não-verbalmente aceitação, interesse, envolvimento e sentimentos empáticos. Lancei mão das medidas terapêuticas de enfermagem: oferecimento de apoio à criança e à mãe (que participou da interação) (20-21); e o estabelecimento de limites, quando procurei descrever o ambiente do centro cirúrgico e o como seriam os procedimentos aos quais ela se submeteria, explicações que lhe delimitariam o espaço físico e o que se esperava dela no centro cirúrgico. As respostas e atitudes da criança, via brinquedo e brincadeiras, mostraram que ela havia compreendido e aceitado a situação, e estava concordando em participar dela ${ }^{(4,9)}$.

\section{$2^{\mathrm{a}}$ interação: fase de desenvolvimento do relacionamento}

\section{Periodo trans-operatório}

Esperei I para a cirurgia na porta do Centro Cirúrgico. Ela chegou tranqüila, no colo da mãe. Chamei-a e ela, me reconhecendo, veio para os meus braços. Entramos no corredor do Centro Cirúrgico, deixando a boneca com a mãe. Levei-a no colo até a sala de operação. Quando chegamos, mostrei-lhe os aparelhos, disse que eram brinquedos e que a gente ia brincar mais ali. Peguei duas luvas de procedimento e fiz balões, brincamos com os dedos das luvas e cantamos músicas infantis, enquanto a equipe ia chegando e sendo apresentada a ela. I os recebia muito bem, pedindo sempre para que todos deixassem a porta fechada como eu havia lhe ensinado.

Pedi para o anestesiologista que a punção venosa fosse feita após a anestesia inalatória, pois isso a pouparia do estresse do procedimento invasivo. Colocamos os eletrodos falando que eram medalhas de ouro, prata e bronze, fomos brincando e sorrindo. Ajudei o anestesista a colocar a máscara inalatória e o oxímetro. I permitiu os procedimentos sem brigas, apesar de ter feito uma expressão meio desconfiada quando colocamos a máscara no seu rosto. Após anestesiada, iniciou-se a cirurgia e não houve 
intercorrência alguma. Durante a cirurgia a equipe cirúrgica disse que a criança esteve muito calma. Segundo eles, nem sempre as experiências de cirurgias infantis são assim.

\section{Análise}

Na chegada de I ao Centro Cirúrgico ela me reconheceu. Fiquei muito feliz com isso e quando, ao chamá-la, ela foi para os meus braços, percebi que funcionei como um ponto de referência para a criança: havia conseguido estabelecer com ela um elo de confiança.

Quando chegamos na sala de operação, identifiquei os aparelhos como brinquedos, utilizei as luvas para brincar e cantamos. Notei que I estava passando por uma situação nova e por vezes ameaçadora, porém, ao brincar com tudo aquilo, ela começava a tratar a situação com tranqüilidade, já que brincar faz parte do seu cotidiano(4). Não deu mostras de estranhamento com o ambiente e nem mesmo com os profissionais, assim como eu mesma, paramentados para a cirurgia.

Ao pedir para que todos fechassem a porta, I estava repassando um ensinamento que, durante as brincadeiras na interação anterior, eu havia lhe passado, comprovando que brincando a criança é capaz de compreender e captar as mensagens que lhe são enviadas, por mais complexas que nos pareçam: utilizando linguagem intelegível para ela - no caso, o brinquedo - I havia compreendido as práticas do Centro Cirúrgico perfeitamente(4,10)

A equipe cirúrgica participou na interação, aceitando utilizar as brincadeiras como forma de comunicar-se com I Posteriormente, anestesiologista e cirurgiões validaram a percepção de que o brinquedo pode ser uma forma de facilitar a compreensão e diminuir o estresse da criança como paciente no Centro Cirúrgico.

Nesta interação utilizei, mediadas pelo brinquedo, as técnicas que estimulam a expressão de pensamentos e sentimentos das experiências vivenciadas $^{(4,10)} \mathrm{O}$ retorno da criança à técnicas foi positivo: ela se expressava brincando, mostrando compreensão e aceitação do que lhe acontecia. A sua hesitação em aceitar a máscara inalatória mostrou que ela experimentou ansiedade diante do objeto estranho que lhe provocaria desconforto, mas entendi que a relação de confiança desenvolvida comigo deulhe segurança para concordar com o procedimento. $\mathrm{O}$ tempo todo utilizei o oferecimento de apoio --- estando o tempo todo ao seu lado, ajudando-a a entender o que lhe acontecia; e o estabelecimento de limites em todos os momentos nos quais ajudei-a a perceber os comportamento que se esperavam dela naquele ambiente.

\section{$3^{\mathrm{a}}$ e $4^{\mathrm{a}}$ interacões: fase de desenvolvimento/ fase de finalizacão do relacionamento}

\section{Recuperação anestésica e pós-operatório}

Terminado a cirurgia, levei I para a sala de recuperação anestésica e esperei que ela se recuperasse. Ao acordar ela chorou um pouco chamando a mãe e queixando-se de dor. Tentei acalmála, permanecendo ao seu lado e explicando sobre o procedimento e o que lhe acontecia ali, porém ela queria a mãe. Então ela foi medicada com analgésico e recebeu alta. Fomos para a enfermaria acompanhadas pela mãe e pelas bonecas, chegando lá a mãe pegou-a no colo e I deixou de chorar.

No dia seguinte fui até a enfermaria pela manhã, ela recebeu-me muito bem, já estava brincando com as bonecas novamente. Conversando com a mãe, ela relatou-me que I havia narrado tudo o que tinha acontecido antes da anestesia, inclusive as pessoas que lá estavam, sem medos nem traumas. A mãe de I ficou bastante grata e, como toda a equipe cirúrgica, também avaliou as interações como muito importantes para a criança. Nesse mesmo dia I recebeu alta e foi para casa.

\section{Análise}

$\mathrm{Na}$ sala de recuperação anestésica, ao acordar sentindo dor, a criança chorou e chamou pela mãe. Minha tentativa de acalmá-la não adiantou muito, pois não supria a falta da mãe diante de uma situação dificil. O choro foi durante um pequeno período. I foi medicada, teve alta da sala de recuperação anestésica e se encontrou novamente com a mãe. Restabelecendo o contato com a mãe, ela parou de chorar $(4,10,20)$ As bonecas continuaram a acompanhá-la. Ao sair da recuperação, ela as recebeu de volta e levou-as para o seu quarto.

No dia seguinte ela me recebeu com alegria, brincando Percebi que não haviam ficado medos nem traumas em relação à minha pessoa e à cirurgia. Ao contar a experiência vivida para a mãe, lembrando de tudo como havia acontecido, I não demonstrou aflições, deixando a mãe bastante contente com o trabalho feito.

Avaliando o desenvolvimento do relacionamento com a criança, senti-me satisfeita com os resultados. Foram atingidos todos os objetivos estabelecidos na fase inicial com a criança e a mãe: prepará-las para o procedimento cirúrgico e oferecer-lhes apoio, visando reduzir a ansiedade de ambas. É freqüente assistir crianças entrando no Centro Cirúrgico aos prantos, precisando ser contidas por restrição fisica, que ainda as agride mais, o que certamente provocará traumas dificeis de superar. Ao ajudar I passar pelos procedimentos cirúrgicos de uma forma mais tranqüila, desenvolvendo com ela uma relação 
terapêutica, penso que consegui ajudá-la a entender o ambiente e os procedimentos cirúrgicos; e usando o recurso do brinquedo para efetivar a comunicação, foi possivel cuidar de forma humanizada, com a sua participação consciente, não obstante o ambiente frio e hostil do Centro Cirúrgico.

\section{CONSIDERAÇÕES FINAIS}

Este estudo faz parte de um projeto da disciplina Relacionamento Terapêutico, cujas atividades foram desenvolvidas durante as atividades práticas supervisionadas da disciplina de Enfermagem em Centro Cirúrgico. O referido projeto terá continuidade no estágio de pediatria, quando poderei. acompanhar outras crianças na assistência peri-operatória. Ao final do trabalho, avalio que atingi os objetivos propostos para o desenvolvimento do relacionamento com I e sua mãe: orientei-as a respeito dos procedimentos; acompanhei a criança em momentos críticos: no préoperatório imediato, durante o procedimento cirúrgico e no pós-operatório imediato; ofereci apoio mantendome ao seu lado na sala cirúrgica e após a anestesia, locais onde ela estaria sem a mãe, em ambiente estranho e submetida a procedimentos agressivos; avaliei com as duas, ao final, os resultados desse acompanhamento. Analiso que utilizei as técnicas de comunicação terapêuticas que estimulam a expressão de pensamentos e sentimentos a respeito da experiência vivenciada, sendo essas técnicas mediadas pelo recurso do brinquedo da dramatização. Ficou claro para mim que essa linguagem abre os canais de comunicação com a criança. Foram utilizadas durante as interações as medidas terapêuticas de enfermagem: oferecimento de apoio à criança e à mãe, e o estabelecimento de limites, os quais ajudaram a ambas a se localizar fisicamente dentro das várias dependências do hospital, compreendendo como adequar-se a esses locais estranhos.

Avalio que, durante cada uma das interações desenvolvidas, pude ter retorno da efetividade da utilização do brinquedo como forma de comunicação: durante todos os momentos a comunicação da criança de 3 anos foi espontânea e clara; percebi que ela compreendia bem o que eu lhe explicava e, mesmo sendo brinquedo e brincadeiras, ela os entendia como parte do que lhe acontecia. Melhor dizendo, mesmo brincando e rindo, ela entendia que o que eu lhe explicava brincando era real. Tanto que ela usou a boneca para lembrar-se de uma experiência hospitalar antiga que lhe acontecera. Em todas as situações a criança manteve esta atitude espontânea e à vontade, aceitando o que lhe acontecia, pois, no meu entender, o trabalho de apoio desenvolvido permitiu-lhe uma certa familiaridade com os objetos hospitalares, o ambiente e os procedimentos. O fato de acompanhá-la até o Centro Cirúrgico, utilizando a boneca como protagonista, permitiu-lhe conhecer e experimentar previamente a ida para a cirurgia, quando se separaria da mãe; mais tarde, quando foi para lá efetivamente, pôde sentir-se segura. No pós-operatório, voltando da anestesia, quando chorou de dor e chamou pela mãe, expressava uma necessidade: sendo atendida, tranqüilizou-se.

O acompanhamento desenvolvido com a criança foi avaliado muito positivamente pela mãe e pela equipe cirúrgica. Porém, o que mais me sensibilizou como um retorno valioso do trabalho foi a tranqüilidade e a espontaneidade da menina quando contou à mãe o que lhe aconteceu no Centro Cirúrgico: sem traumas, rindo, brincando, ela se lembrou de tudo. Este momento representou para mim a validação dos resultados do apoio oferecido à criança, confirmando a importância da comunicação terapêutica e do brinquedo, os quais lhe permitiram lidar de forma tão realística e adequada com a realidade daqueles procedimentos invasivos em ambiente estranho.

Este estudo é apenas um primeiro de uma série, com outras crianças. E um estudo de caso, particular, sem pretensões a conclusões definitivas. Porém, comparando-se esses dados com os da literatura, penso que há claras indicações a respeito da efetividade em se utilizarem os recursos da comunicação terapêutica associados ao brinquedo na assistência de enfermagem à criança, nas várias fases do desenvolvimento, individualizando essa comunicação segundo as necessidades e características da cada criança. Tratase sempre de falar à criança no modo que ela compreende, utilizando a linguagem do seu universo: o brinquedo.

\section{REFERÊNCIAS BIBLIOGRÁFICAS}

(1) Ruesch J. Comunicación terapêutica. Buenos Aires : Paidós; 1964-

(2) Peplau HE. Interpersonal relations in nursing. New York: G.P. Putmans; 1987

(3) Stefanelli MC. Comunicação com paciente: teoria e ensino. 2ed. São Paulo: Robe Editorial; 1993.

(4) Whaley LF, Wong DL. Enfermagem pediátrica: elementos essenciais à intervenção efetiva. 2 ed. Rio de Janeiro: Guanabara; 1989.

5) Gonzaga, MLC, Arruda EN. Fontes e significados de cuidar e não cuidar em hospital pediátrico. Rev Lat Am Enferm 1998; 6 (5):17-26. 
6) Duarte ERM, Muller AM, Bruno SMA, Duarte ALS. A utilização do brinquedo na sala de recuperação: um recurso a mais para assistência de enfermagem à criança. Rev Bras Enferm 1987; 40 (1):74-81.

(7) Lebovici S, Diatkine R. Significado e função do brinquedo na criança. 3ed- Porto Alegre: Artes médicas; 1988.

(8) Françani GM, Zilioli D, Silva PRF, Santana RPM, Lima RAG. Prescrição do dia: infusão de alegria. Utilizando a arte como instrumento na assistência à criança hospitalizada. Rev Lat Am Enferm 1998; 6 (5):27-33.

(9) Sadala MLA, Antonio ALO. Interagindo com a criança hospitalizada: utilização de técnicas e medidas terapêuticas. Rev Lat Am Enferm 1995; 3 (2):833-92-

(10) Winnicott DW. O brincar e a realidade. led. Rio de Janeiro: Imago Editora Ltda; 1975.

(11) Ribeiro CA. O brinquedo terapêutico na assistência criança hospitalizada: significado da experiência para o aluno de graduação em enfermagem. Rev Esc Enferm USP 19981;32 (1): 73-9.

(12) Pinheiro MCD, Lopes GT. A influência do brinquedo na humanização da assistência de enfermagem à criança hospitalizada. Rev Bras Enferm 1993; 46(2):117-131.

(13)Ribeiro CA. O efeito da utilização do brinquedo terapêutico, pela enfermeira pediatra, sobre o comportamento de crianças recém-hospitalizadas. Rev Esc Enferm USP 1991; 25(1): 41-60

(14) Schmitz EMR. Enfermagem em pediatria e puericultura. Rio de Janeiro: Atheneu; 1989.

(15) Angelo M. Enfermagem em unidade de terapia intensiva pediátrica: além de atividades técnicas .Rev Esc Enferm USP $1980 ; 14(3): 275-9$

(16) De OliveiraVT, Cassiani SH. O processo de comunicação na administração de medicações injetáveis sob a perspectiva da interação entre mãe-criança e auxiliares de enfermagem. Rev Lat Am Enferm 1997; 5 (4):61-7.

(17) Lorençon M. Auto-percepção de aluna de enfermagem ao desenvolver relação de ajuda com familiares de criança em fase terminal. Rev Lat Am Enferm 1998: 6 (4):57-65.

(18) MazzaVA. A comunicação não-verbal como forma de cuidado de enfermagem: ensino e prática. [dissertação]. Florianópolis (SC): Faculdade de Enfermagem da Universidade Federal de Santa Catarina; 1998.

(19) Novelli MC. Relato e análise de comunicação com paciente pediátrico. [monografia] Botucatu (SP]: Curso de Graduação em Enfermagem FM UNESP, 1992 [mimeografado].

(20) Pereira EC. Relato de experiência com criança hospitalizada. [monografia] Botucatu (SP]: Curso de Graduação em Enfermagem FM UNESP, 1992 [mimeografado].

(21) Burns M. Creating a self passage: the meaning of engagement for nurses caring for children and their families. Issues Compr Pediatr Nurs 1994; 17 (4):211-21
Richardson J, Burnard P Talking with children: some basic counselling skills. Prof Care Mother Child 1994; 4(4): 111-4.

(23) Neira Huerta EP. Brinquedo no hospital. Rev Esc Enferm USP 1990; 24(3): 319-328.

(24) Ziegler DB, Prior MM. Preparation for surgery and adjustment to hospitalization. Nurs Clin North Am 1994; 29(4): 655-69.

(25) Rossen BE, Mckeever PD. The behaviour of preschoolers during and after brief surgical hospitalization. Issues Compr Pediatr Nurs 1996; 19(2):121-33.

(26) Bar-Mor G. Preparation of children for surgery and invasive procedures: milestones on the way of success. $J$ Pediatr Nurs 1997; 12(4):252-5.

(27) Lancaster KA. Care of pediatric patient in ambulatory surgery. Nurs Clin North Am 1997 ; 32(2):441-55.

(28) Mooney KM. Perioperative management of the pediatric patient . Plast Surg Nurs 1997; 17(2): 69-73, 74-5.

(29) Ortigosa Quilles JM, Mendez Carrillo FX, Vargas Torcal F. Repercussion de la preparation psicológica a la cirurgia pediátrica sobre la recuperation postquirúrgica. An Esp Pediatr 1998; 49(4): 369-74.

(30) Sundeen SJ, Stuart,GW, Rankin ED, Cohen SA. Nurseclient interaction: implementing the nursing process. Saint Louis: CV Mosby, 1985.

\section{Artigo recebido em 08/11/00}

Artigo aprovado em 10/07/02 